Review

\title{
Atomic Force microscopy techniques to investigate activated food packaging materials
}

\author{
Francesco Marinello $^{\mathrm{a}}$, Antonietta La Storia ${ }^{\mathrm{b}}$, Gianluigi Mauriello $^{\mathrm{b}, *}$, Daniele Passeri $^{\mathrm{c}}$ \\ ${ }^{a}$ Department of Land, Environment, Agriculture and Forestry, University of Padova, Legnaro, Italy \\ ${ }^{\mathrm{b}}$ Department of Agricultural Sciences, University of Naples Federico II, Italy \\ ${ }^{\mathrm{c}}$ Department of Basic and Applied Sciences for Engineering, Sapienza University of Rome, Italy
}

\section{A R T I C L E I N F O}

\section{Keywords:}

Scanning probe microscopy

High resolution imaging

Innovative food packaging

Activated plastic materials

\begin{abstract}
A B S T R A C T
Background: Since its invention, Atomic Force Microscopy has demonstrated to be one of the most interesting and useful techniques in many fields such as biology, optics and electronics to investigate nanoscale phenomena. Not only can it provide high resolution three-dimensional imaging of surfaces, but it also allows quantitative characterization of topographies, forces, mechanical and viscoelastic properties of interfaces at nanometer level. Scope and approach: Here we review current literature in the food packaging field where AFM has been proposed for the quantitative characterization of surfaces with functional layers allowing for exploitation of preservative properties as a result for example of higher permeability or antimicrobial activity. In fact, probing microscopes allow analysis of physical or mechanical properties of interfaces providing relevant information at the nanoscale with regard to different parameters such as dimensions, shapes, evolution and adhesion. Furthermore, recent developments in AFM have shown how fast imaging techniques can be implemented to allow time evolution description even at relatively high temperatures. What we aim is to establish how AFM is effectively promising in the research and development of innovative food packaging.

Key findings and conclusions: AFM is largely used to characterize (bio)plastic materials for food packaging but also the comprehension of materials modification due to their activation is approached by using AFM, frequently combined to others instrumental analysis. In particular, even though AFM is basically used for topographical analysis of activated plastic materials, new and advanced AFM analysis are carried out for the characterization of different chemical and physical properties.
\end{abstract}

\section{Introduction}

Until the year 2004 packaging material for food was considered, within the European Union (EU), something that must be inert with respect the food in contact or to the headspace. In that year an epochal change took place in the field of food packaging. Indeed, the European Parliament promulgated on 27th October 2004 the Regulation N. 1935/ 2004 "on materials and articles intended to come into contact with food and repealing Directives 80/590/EEC and 89/109/EEC" (The Commission of the European Communities, 2004). With this regulation EU, a bit behind other countries like United States of America and Japan, finally introduced the concepts of active and intelligent packaging. At point (4) of preliminary considerations it is reported that "New types of materials and articles designed to actively maintain or improve the condition of the food (active food contact materials and articles) are not inert by their design, unlike traditional materials and articles intended to come into contact with food. Other types of new materials and articles are designed to monitor the condition of the food (intelligent food contact materials and articles)". In the next point (5), dedicated to the active packaging, regulation reports that "Active food contact materials and articles are designed to deliberately incorporate 'active' components intended to be released into the food or to absorb substances from the food. They should be distinguished from materials and articles which are traditionally used to release their natural ingredients into specific types of food during the process of their manufacture, such as wooden barrels". In these two points, it is very well clarified what does it mean active food packaging.

Some more or less recent reviews describe different types of active packaging investigated during last decade and their application to different types of foods. As a matter of fact, recently Fang, Zhao, Warner, and Johnson (2017) reviewed all the active and intelligent packaging solutions for meat products. Dobrucka and Cierpiszewski (2014)

\footnotetext{
* Corresponding author. Via Università 100, 80055, Portici, Italy.

E-mail address: giamauri@unina.it (G. Mauriello).
} 
reviewed investigations on intelligent and active packaging, without focusing on specific foods as well. Finally, an industry-focused review on intelligent and active food packaging updated to 2012 was published by Pereira de Abreu, Cruz, and Losada (2012).

Even though numerous different types of active packaging are described in literature, most of research is addressed on two main functionalities of activated food packaging: antimicrobial and oxygen scavenging. However, smart solutions are also described for the carbon dioxide emitters, humidity absorbers, odour absorbers/emitters and ethylene absorbers. In all the cases, functionalization can modify some features of the neutral packaging material, both for polyolefins (synthetic plastics) and bioplastics. Among them there is the permeability, weldability, elasticity, transparence and the surface topography. Even though scanning electron microscopy (SEM) is the standard tool for the investigation of surface plastic film morphology, Atomic Force Microscopy (AFM) analysis was successfully introduced in the last years for this purpose. In a concise but effective way, AFM was described like an analytical tool to measure surface features and mechanics of both synthetic and biological materials (Jones, 2016). Here we first briefly review the two main types of active food packaging, obtained by using antimicrobials and oxygen scavengers, and then we review more in depth the application of AFM analysis to activated materials aimed to food packaging design.

\section{Active food packaging}

\subsection{Antimicrobial packaging}

Antimicrobial food packaging has shown to be an effective strategy among active packaging to inhibit spoilage proliferation and to ensure food safety against pathogenic microorganisms. Each antimicrobial substance generally exhibits a specific bactericidal or bacteriostatic action against different microorganisms and this specificity must be careful considered to decide the final application of the developed antimicrobial packaging. Furthermore, the chemical interaction between agents and packaging polymeric material as well as the food composition, process and storage conditions play an important role in implementation of active packaging. Therefore, the development of an antimicrobial packaging is an articulated and complex process, as evidenced by the numerous researches that have been conducted in this field (Mauriello, 2016).

In a recent review on this journal Fang et al. (2017) delineate the four main categories of antimicrobial packaging for meat products. However, the same categories could be recognized for all food products: i) incorporation of antimicrobial agents (AA) in a sachet or pad able to be released within packaging headspace inside the package; ii) incorporation of AA into the polymers; iii) coating of packaging material with a varnish that vehicle the AA; $i v$ ) polymers that are inherently antimicrobial.

In all the cases AA could be volatiles and non-volatiles, natural or synthetic as well as packaging material could be manufactured with traditional plastics or compostable materials (i.e. bioplastics and paper).

The first category has been comprehensively reviewed by Otoni, Espitia, Avena-Bustillos, and McHugh (2017), which underline that the AA used in this type of active packaging are basically volatile compounds, and among them essential oils (EOs) have been more diffusely tested. A representative work reporting typical pro and cons of this type of packaging describes the antimicrobial activity of oregano essential oil in sachets to package sliced bread against yeast and molds, but the negative consumer acceptance of the product (Passarinho et al., 2014). Indeed, although essential oils as well as the common volatile AA (e.g. ethanol and allyl isothiocyanate) are considered safe for human consumption and effective against numerous microorganisms, their application may be limited because of effect on the sensory evaluation. Definitively, no structural modification of packaging materials occurs in this category of antimicrobial packaging.

On the contrary, huge change could happen when AA are incorporated into the packaging polymers. In this second category, AA are usually added during the process (i.e. extrusion or casting) for the production of packaging materials. Nevertheless, many AA are sensitive to high processing pressure and temperature used during plastic film production. As a matter of fact, reported a certain loss of antimicrobial activity toward Staphylococcus aureus of thymol and carvacrol included in polypropylene treated at $190^{\circ} \mathrm{C}$ for $18 \mathrm{~min}$ for film formation. However, the use of ethylen-vinyl-acetate copolymer (EVA) in the master-batch can significantly reduce the extrusion temperature. In fact, no depletive effect was registered on biological activity of Allium sativum EO, toward Escherichia coli and Staphylococcus aureus, in blown film obtained by low-density-polyethylene (LDPE) and EVA (Sung, Sin, Tee, Bee, \& Rahmat, 2014). High percentage of antimicrobial activity was also preserved during high temperature extrusion process of LDPE added of carvacrol and protecting modified clay Nanomer I.28 (Persico et al., 2009). Nanoparticles as carrier have received great attention in recent years. Tornuk, Hancer, Sagdic, and Yetim (2015) implemented the use of nanoclays (montmorillonite and halloysite) to carry carvacrol, thymol, and eugenol, in different mixtures, in linear low density polyethylene (LLDPE) in win-screw extrusion followed by blow molding; this antimicrobial packaging was able to reduce the spoilage microbiota of traditional Turkish type fermented sausage ensuring antimicrobial effect during ripening. Instead, total loss of antimicrobial activity was registered when an antilisterial bacteriocin was included in a polyethylene (PE) film by an extrusion process on pilot plant (Mauriello \& Villani, 2011). The use of biopolymers is the best choice to incorporate AA in packaging films. Natural polymers such as chitosan, polysaccharide, polylactic acid, proteins, gums, soy, alginate-based, whey are more studied to include different AA (i.e. various organic acids, enzymes and bacteriocins, essential oils and their components, silver zeolite, allyl isothiocyanate, $\mathrm{TiO}_{2}$ nanoparticles) for food packaging purpose (Valdés, Ramos, Beltrán, Jimémez, \& Garrigós, 2017). Moreover, the microincapsulation of AA could improve the stability and kinetic efficiency in extrusion of biopolymers (Guarda, A., Rubilar, J. F., Miltz, J., \& Galotto, M. J., 2011; Maresca et al., 2016). In this category of antimicrobial packaging, the immobilization in biopolymers of viable microorganisms like the bacteriocin producer strains (Leonard et al., 2015) or bacteriophages (Radford et al., 2017) could be counted.

Heat-sensitives AA can be applied by coating on the surface of food packaging material, to constitute the third category of antimicrobial packaging. Recently, Bastarrachea, Wong, Roman, Lin, and Goddard (2015) reviewed the key technologies for active packaging coatings.

Reasonably, EOs and bacteriocins are the AA more tested in this group of antimicrobial packaging. Even though both AA have been mainly applied for bioplastic coating in the last years, numerous works report the use of traditional plastic. Atarés and Chiralt (2016) reviewed the impact of EOs on the properties of edible films and coatings. On the other hand, promising industrial application by coating of bacteriocins on PE films were performed by Ercolini et al., 2010; Ercolini, La Storia, Villani, and Mauriello (2006); Ferrocino et al. (2013); La Storia, Mauriello, Villani, and Ercolini (2013); Mauriello, De Luca, La Storia, Villani, \& Ercolini, 2005; Mauriello, Ercolini, La Storia, Casaburi, and Villani (2004). AFM analysis is particularly suitable in this category of packaging because of topography modification of activated materials.

Last category of antimicrobial packaging is in our opinion of too scarce interest for food packaging field to be discussed in this review. Indeed, even though some authors describe the antimicrobial efficacy of some natural and synthetic polymers used for food packaging, this property is few significant to effectively control any pathogen or spoilage microorganism in real food systems. 


\subsection{Oxygen scavenging packaging}

Out of microbial food spoilage, oxidation is the main reason of organoleptic decay of foods. The presence of undesired oxygen may result from inadequate or insufficient evacuation during the packaging process, presence in the food itself or the packaging material and release into the headspace, permeation through the package, introduction of air due to a poor sealing, or microperforations in the packaging material (Pereira de Abreu et al., 2012). For this reason, several antioxidant food additives are used, like ascorbic acid and his salts and tocopherols. However, oxidation of food can be prevented by applying oxygen scavengers on/in the plastic material used for food packaging. As a matter of fact, main benefits in the use of oxygen scavengers are reported by Cichello (2015) in a recent review. Even though not all free radical scavengers are antioxidants, here we use the term oxygen scavengers grouping both reactive oxygen species (ROS) scavengers and antioxidants. Oxygen scavengers are basically compounds able to react with oxygen reducing its concentration. They can be used in various forms: sachets in headspace, labels, or directly incorporated into package material and/or closures (Brody, Bugusu, Han, Sand, \& McHugh, 2008). Modification of surface topography and structure of films occurs only in the case of direct incorporation of scavengers, of course. Oxygen scavengers include chemical and enzymatic systems. Most chemical systems are based on the use of iron powder in which the oxidation reaction of iron or ferrous salts leads to the formation of stable oxidized iron products.

The general reaction for oxygen scavenging by iron powder, the socalled rusting process, is the following:

$4 \mathrm{Fe}+3 \mathrm{O}_{2}+6 \mathrm{H}_{2} \mathrm{O} 4 \mathrm{Fe}(\mathrm{OH})_{3}$

in which is clear that the presence of water is a topical condition for a correct progress of the iron oxidation reaction (Cichello, 2015).

Even though the ferrous iron is mainly used under the form of sachets, plastic materials containing iron nanocomposites have been largely investigated in the last period (Khalaj, Ahmadi, Lesankhosh, \& Khalaj, 2016). Moreover, cobalt salts have been also tested for their oxygen scavenging potentiality and development of active packaging solutions (Damaj, Joly, \& Guillon, 2015; Galdi, Nicolais, Di Maio, \& Incarnato, 2008).

Some enzymatic systems showed their ability to efficiently reduce oxygen concentration such as to be taken into account for active food packaging application. For example, Wong, Andler, Lincoln, Goddard, and Talbert (2017) proposed a hydrophobic modified glucose oxidase to obtained an oxygen scavenging polymer for coating application. Coating procedure is considered the best option for this purpose because enzymes can be incorporated into a coating layer, which can be applied directly onto the packaging material (Johansson et al., 2014). Finally, good scavenging capacity was shown by the natural antioxidant alpha-tocopherol after microencapsulation in poly (lactic) acid matrix with a potential application for active packaging development (Scarfato, Avallone, Galdi, Di Maio, \& Incarnato, 2017).

\section{Atomic Force Microscopy (AFM)}

AFM is one of the elected techniques for fine reconstruction of surface topographies with nanometer or sub-nanometer vertical and lateral resolution (Marinello, Bariani, Carmignato, \& Savio, 2009). This is made possible by a tip with a radius of curvature typically smaller than $10-20 \mathrm{~nm}$ and attached to the free end of a flexible cantilever, which is scanned over the sample surface with a probing force as low as a few $\mathrm{nN}$. The interaction between the probe and the surface as well as the modulation of the interacting force allow one to investigate several physicochemical properties of the sample surface. The most typical result is certainly the generation of a topography map. Indeed, AFM can operate under different environmental conditions such as vacuum,

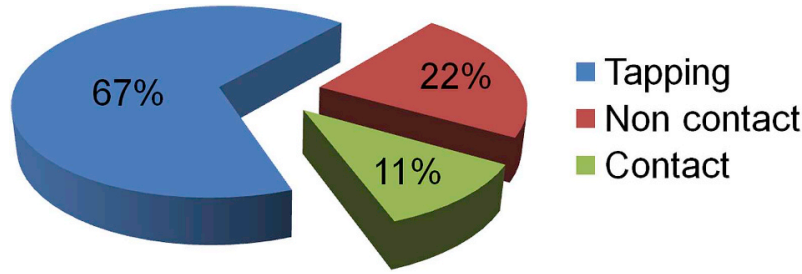

Fig. 1. Scanning modes implemented in connection with analyzed works: noncontact and intermittent (or tapping) are preferred with respect to contact mode.

liquid, air or different gases, both at low and high temperatures (Karam, Jama, Dhulster, \& Chihib, 2013), allowing characterization of stiff surfaces as well as soft interfaces or biological samples. For these reasons, such instruments are often applied for characterization of packaging materials, and relating to the topic of the present review, of activated food packaging materials. This is more typical in the case of materials with active antimicrobial behavior, but also other active principles are described. This is particularly true in the cases of noncontact or tapping modes (chosen in the majority of cases, as highlighted in Fig. 1) where interaction forces as low as tenths of nanoNewtons arise between the tip and the scanned surface.

Generated maps can be implemented for both qualitative inspection of interfaces and quantitative estimation of surface dimensions such as roughness calculation, nanoparticles dimensions or density, as highlighted by proposed bibliography (Fig. 2). Additionally, AFM can be implemented to monitor and quantify the evolution of surfaces after treatments, to estimate interaction forces or to understand antimicrobial or other active mechanisms of surfaces, as discussed in following paragraphs.

AFM is seen as a technique which is complementary to other inspection instruments. Indeed, due to the fact that it provides high resolution imaging but with slow stabilization and scanning times (Marinello, Balcon, Schiavuta, Carmignato, \& Savio, 2011), in most of cases it is used in combination with electron or optical microscopy techniques, which conversely can provide fast characterizations in relatively large areas, but with no information on surface three-dimensional topographies. As in the case of other microscopy techniques, in $26 \%$ of analyzed bibliography AFM is implemented only for qualitative imaging of surfaces. On the other hand, in most of cases referenced works report exploitation of quantitative characterization, through both roughness or geometrical indexes (Fig. 3). Indeed, such parameters can highlight morphological differences between different treatments, or describe the evolution in the vertical elevation of surface features present in treated surfaces. Over $65 \%$ of analyzed works present roughness parameters, and $55 \%$ of works focus on root mean square roughness (Sq or RMS or Rq). As defined by ISO 25178, Sq is computed as

$S q=\sqrt{\frac{1}{A} \iint_{A} z^{2}(x, y) d x d y}$

Sq represents the standard deviation of heights, and provides a

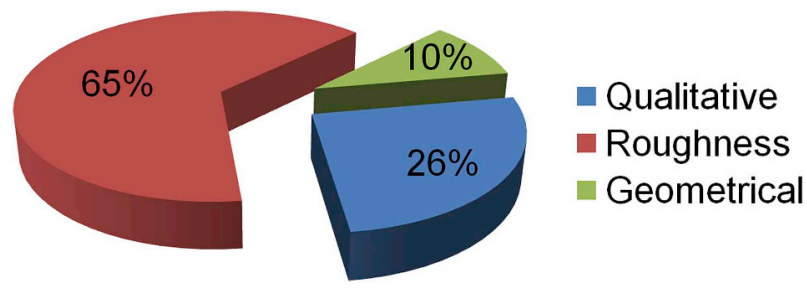

Fig. 2. Atomic Force Microscopy contributes to analyzed works, mainly encompassing qualitative characterization, roughness analysis or geometrical dimensioning. 


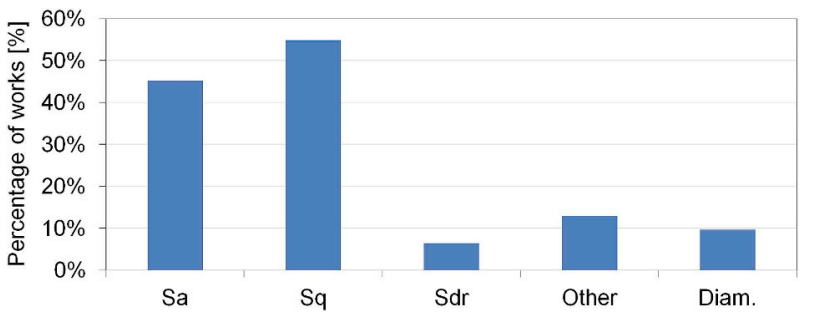

Fig. 3. Roughness and geometrical parameters extracted from AFM scans in connection with analyzed works.

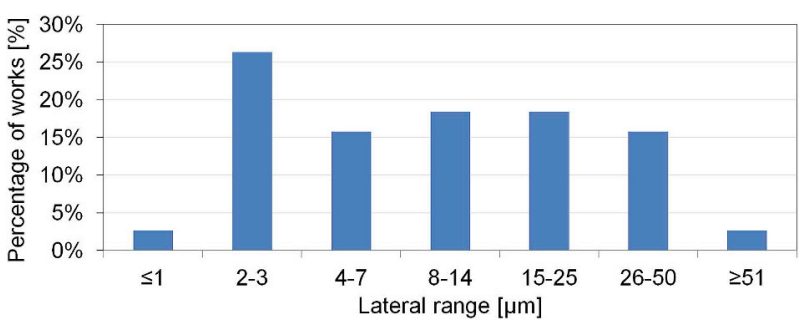

Fig. 4. Measuring lateral ranges of scanned topographies reported in referenced papers.

measure of the amplitude of peaks and valleys recognizable in the surface.

The second most used roughness parameter is average roughness Sa (or Ra), computed in agreement with ISO 25178 as:

$S a=\frac{1}{A} \iint_{A}|z(x, y)| d x d y$

Sa is the arithmetical mean height of a surface and expresses, as an absolute value, the difference in height of each position compared to the arithmetical mean of the surface. Compared to Sq, Sa is less sensitive to large peaks or deep valleys, and is therefore not suitable to quantify localized surface modifications.

Packaging surface represent the interface where relevant reactions are taking place. Since the entity of reactions is often proportional to the total interface area, parameters quantifying total surface development are implemented: specifically Sdr is used for the scope. Indeed, it is calculated as:

$S d r=\frac{1}{A} \iint_{A} \sqrt{\left[1+\left(\frac{\partial z(x, y)}{\partial x}\right)^{2}+\left(\frac{\partial z(x, y)}{\partial y}\right)^{2}\right]}-1 d x d y$

Sdr therefore expresses the percentage of the definition area's additional surface area contributed by the topography as compared to the projected area.

Other parameters are also interesting, such as the total amplitude of the surface topography or the skewness of the height distributions, but are used only in a lower of referenced works.

With regard to geometrical characterization, the most used index is the diameter. Indeed, active packages often implements micro- or nanofibers and particles, which are typically best characterized by such parameter.

The area of scanned topographies is typically depending on the functional dimensions of analyzed surface topographies. In the case of active packaging, surface features are typically ranging between a few tens of nanometers up to a hundreds of nanometers and only in some cases to a few microns. For this reason, scan ranges are rarely smaller than $1 \times 1 \mu \mathrm{m}^{2}$, while are most typically comprised between $2 \times 2 \mu \mathrm{m}^{2}$ and $20 \times 20 \mu \mathrm{m}^{2}$ (79\% of images of referenced papers). Resolutions are proportional to scan ranges. Indeed, AFM images are generally scanned with a $512 \times 512$ points resolutions corresponding to $4 \times 4$ to $40 \times 40$ $\mathrm{nm}$ lateral sampling in the same given ranges.

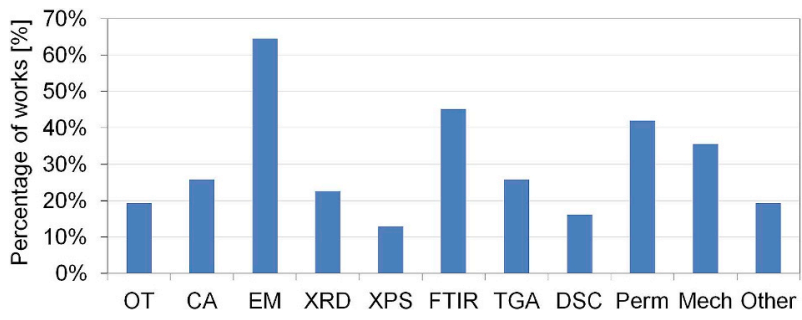

Fig. 5. Measurement technique associated to AFM analyses. OT: optical techniques; CA: contact angle; EM: scanning or transmission electron microscopy; XRD: x-ray diffraction; XPS; x-ray photoelectron spectroscope; FTIR: Fourier transform infrared spectroscopy; TGA: thermogravimetric analysis; DSC: differential scanning calorimetry; Perm: oxygen or water vapor permeability; Mech: mechanical characterization. Other techniques include dynamic light scattering, solubility, gas chromatography, etc.

Topographical and morphological characterization is mainly related to the external surface or, in some cases, up to a few hundreds of nanometers depth; furthermore, treatments or activation processes are done on the interface of polymer films which have to maintain their mechanical properties. For such reason AFM analyses are often associated to universal testing machine equipped with load-cells, needed to determine elastic modulus, tensile strength and elongation-at-break of those films (see Fig. 4).

The functional process for activated packaging often works through a modification of permeability or wettability: for this reason, AFM measurements are often associated to oxygen or water vapor permeability or to contact angle analyses. Finally, other optical (such as Fourier transform infrared spectroscopy, x-ray diffraction or x-ray photoelectron spectroscopy) or non-optical analyses (such as thermogravimetric analysis or differential scanning calorimetry) are often carried out in combination with AFM to complete characterization of active layers. Coupling of AFMs with other instruments for referenced papers are graphically reported in Fig. 5.

\subsection{Qualitative characterization}

AFM not only can analyze samples with no need for dehydration or coating, but also provides a three-dimensional rendering of surface topography. For such reasons, it is often used in substitution or in addition to SEM techniques for visualization and qualitative characterization of surfaces, particularly in the case of activated packaging exhibiting antimicrobial activity.

The presence of polylactide nanoparticles in a chitosan matrix, appearing smooth with SEM, was evidenced as a contoured structure by AFM (Basu et al., 2017).

Biodegradable films of chia by-products incorporated with clove essential oil appeared as non-homogeneous, non-compact, and rough film networks after AFM imaging (Capitani et al., 2016). AFM allowed visualization of polysaccharide crystal enclosing polysorbate-thymol micelles in a film matrix, which eventually promote radical scavenging and antibacterial activity in a potato starch dispersion (Davoodi, Kavoosi, \& Shakeri, 2017). Furthermore, AFM was used to qualitatively characterize different morphologies of ethylene vinyl alcohol copolymer and chitosan polymers mixture films. In particular, AFM evidenced formation of protrusions and indentations due to introduction of zinc oxide nanoparticles embedded in the film surface, causing an enhancement in barrier properties (Sadeghi \& Shahedi, 2016).

Activated packaging is obtained also compounding additives in the polymeric matrix during the extrusion process. AFM imaging is here useful to show and characterize the distribution of such additives in contrast with the polymer amorphous or semi-crystalline matrix, as in the case of natural antioxidant additives into linear low-density polyethylene (Koontz et al., 2010) or in the case of synthetic phenolic antioxidant added to a poly (lactic acid) film (Jamshidian et al., 2012a). 


\subsection{Quantitative characterization}

If by one side AFM techniques allow imaging of surfaces with fine detail resolution and with minor impact due to sample preparation, on the other hand AFMs are more generally applied for the possibility of estimation quantitative information, particularly in the case of antimicrobial packaging.

This is explicitly done by Barish and Goddard (2011), who propose AFM to quantify modifications of surfaces following four common physical and chemical methods for the functionalization of polyethylene films. Roughness modifications are then associated to enables changes in materials' adhesion, wettability, chemical functionality and bioactivity, and are therefore relevant in the field of active packaging. Other authors similarly implemented AFM to characterize surfaces with active antimicrobial aptitude. Sadeghnejad, Aroujalian, Raisi, and Fazel (2014) studied surface modification of polyethylene films by corona air plasma to enhance subsequent coating of silver nanoparticles on the surface of treated film. The study shows how the corona treatment increases roughness of low-density polyethylene (LDPE) films, more than doubling in terms of Sa and Sq, allowing an increase of the following coating silver and a subsequent increase in the amount of released silver from the coated films with promising antibacterial activity against gram positive and negative bacteria. Saini, Falco, Belgacem, and Bras (2016) tested a new cationization pretreatment on microfibrils of cellulose which confers active antimicrobial properties, verified against both Gram positive and Gram negative bacteria. In this study, AFM not only provides qualitative information on microfibrils uniformity of distribution, but also allows quantitative estimation of their evolution after activation in terms of length (few microns) and diameters (few tens of nanometers). Atmospheric pressure plasma is also often applied in industrial processes. With regard to food packaging, it can be implemented to activate polymeric films (mainly polyethylene and polypropylene) with an antimicrobial aptitude: AFM analyses can quantify roughness enhancement which helps deposition and assembling with synthetic preservatives (as potassium sorbate) or natural antimicrobial substances (mainly chitosan) as described by Theapsak, Watthanaphanit, and Rujiravanit (2012) and Lei et al. (2014). Cold plasma in nitrogen atmosphere was also studied by Stoleru et al. (2016) and compared to gamma irradiation treatment: AFM helped characterization of higher roughness in the first case, which allowed a higher degree of chitosan grafting.

Most often the functionalization and activation of packaging is achieved as a consequence of dispersion of active substances into the packaging material or at its interface in the form of deposited micro or nano-layers. In this case, the role of AFMs is mainly devoted to the quantification of roughness, of total interface or on characterization of surface homogeneity to allow homogeneous antimicrobial behavior over the treated surface.

Still in the case of chitosan, both possibilities have been studied. Indeed, Wu et al. (2016) discusses how free-radical-induced grafting of gallic acid onto chitosan can be used for film-forming solutions of chitosan gallate with increased antioxidative and antimicrobial efficacy. Here AFM can highlight surface modifications, even though in this case alternative advanced AFM techniques (Marinello, Schiavuta, Vezzù, Patelli, Carmignato \& Savio, 2011) could provide more information related to deeper layers, as discussed in next paragraph. The same (Wu et al., 2017) and other research groups (Hosseini, Rezaei, Zandi, \& Farahmandghavi, 2016; Yin et al., 2016) propose chitosan also in the form of nanoparticles deposited on packaging interfaces. Similarly, Dehnavi, Aroujalian, Raisi, and Fazel (2013) studied deposition of silver nanoparticles on polymer films to be applied as antimicrobial packaging.

In these works implementation of AFM is useful not only to verify the homogeneity of dispersion of nanoparticles mainly through roughness analyses on deposited packaging surfaces, but also to characterize their diameter. In fact, the average size of nanoparticles is relevant for several reasons. Firstly, the rate between surface and volume, is approximately given by:

$\frac{S}{V}=\frac{4 \pi r^{2}}{4 / 3 \pi r^{3}}=\frac{3}{r}$

Since reactions take place at the interface, the lower is the radius the higher is the rate and the higher is the reactivity of nanoparticles, with improved interactions with microbial cell wall. Secondly, nanoparticles are used in some cases to encapsulate other active substances such as lysozyme proteins (Wu et al., 2017), therefore their size determines the encapsulated amount. Finally, they can help mechanical and thermal stability of micro and nano-layers thus acting as reinforcing coatings or fillers, as reported by Salarbashi et al. (2016), where zinc oxides nanoparticles are used in combination with soluble soybean polysaccharide thin films or by Chaichi, Hashemi, Badii, and Mohammadi (2017) where the increase of tensile strength of produced films is attributed to the formation of a network of cellulosic nanoparticles. Increase of mechanical and barrier properties of active poly-(lactic acid) antioxidant films were seen also after recrystallization process of ascorbyl palmitate (Jamshidian et al., 2012b), with formation of crystals structures characterized in terms of sizes and average roughness thanks to AFM analyses.

AFM can in general provide relevant information not only when nanoparticles mono- or multi-layers are deposited on packaging interfaces, but more in general whenever composite materials are achieved after deposition of nano- micro- or thin-layers, achieving in most of cases active antimicrobial behavior and in some cases also increase of barrier efficiencies. In most of cases (Corradini et al., 2013; Denis-Rohr, Bastarrachea, \& Goddard, 2015; Ghasemlou et al., 2013; Javidi, Hosseini, \& Rezaei, 2016; La Storia et al., 2013; Ortega-Toro, Jiménez, Talens, \& Chiralt, 2014; Salarbashi et al., 2013; Shojaee-Aliabadi et al., 2013) AFM is implemented in order to show the evolution or the reorganization of the surface following different layers depositions and quantified by the different roughness parameters discussed above. In some cases, scanning probe analyses highlights formation of micro or nano cavities which can host specific components with active antimicrobial function (Gouvea, Mendonça, Soto, \& Cruz, 2015; Grigoriu, Luca, Horoba, \& Dunca, 2013). Besides visualization, it is interesting to note how AFM measurements allow quantification of shape, volume and area of such micro-pockets, which are relevant data for quantification and modulation of deposited components and release rates. This is has been mainly discussed by Xing et al. (2016): here the research group quantifies the number of micropores detected on a chitosan coating membrane through AFM analyses and indicate how such micropores can be used as carriers of active compounds.

\section{Advanced AFM techniques and perspectives}

The main use of AFM in food packaging technology is undoubtedly the morphological study of surfaces. Nonetheless, food packaging technology could take advantage of a number of advanced AFM techniques for the characterization of different chemicals (e.g., compositional variations and identification of molecular structures) and physical (mechanical, electric, magnetic, thermal) properties, which are well-established and widespread in other technological fields. Despite hardly used in food packaging characterizations, some of these AFMbased techniques have the potential to give a significant contribution (e.g. evaluating the dispersion of nanofillers into the matrices and the physical properties of the resulting nanocomposites, studying food/ packaging interactions and mass transport, and analyzing antibacterial properties of advanced active packaging materials). Below, an overview is given of some advanced AFM-based techniques which may have promising applications in food packaging. 


\subsection{Phase imaging of food packaging materials}

Combined with standard topographic reconstruction in AFM tapping mode, phase imaging is one of the most popular techniques used in the study of nonhomogeneous compliant materials (e.g., polymers or biological samples), as the contrast in such phase images reflects variations in the physical properties on the surface (García \& Pérez, 2002). In phase imaging, the phase lag between the cantilever excitation and deflection signal is mapped simultaneously to the standard topographic imaging in tapping mode. In these conditions, being the cantilever oscillation amplitude constant due to the presence of the feedback, the phase shift reflects changes in the energy dissipation during a cantilever oscillation cycle (Bar, Brandsch, \& Whangbo, 1998). Thus, the contrast in phase images allows one to visualize lack of homogeneity on sample surface. Phase imaging is particularly suitable for the study of polymer blends (Raghavan, Gu, Nguyen, VanLandingham, \& Karim, 2000), for the identification of soft nanometer sized features on stiff substrates (Ingallina et al., 2016), or for the identification of nanofillers in polymer-based nanocomposites (Maiti \& Bhowmick, 2006).

As for materials of interest in food packaging, AFM phase imaging has been used for instance to visualize lipid particles of different surfactant (sorbitan monopalmitate, monostearate, and mono-oleate) on the surface of corn starch-glycerol based films, attributed to lipid coalescence and creaming during film drying and subsequent solidification (Ortega-Toro et al., 2014). Also, it has been used to detect sub-micrometer features in LLDPE films loaded with natural antioxidants, i.e., alpha-tocopherol, quercetin, and their cyclodextrin inclusion complexes, which are studied for applications in food packaging to delay oxidative degradation of the polymer and the onset of oxidation of the packaged food during storage (Koontz et al., 2010). In addition to the study of food packaging surfaces, phase imaging can be used also to investigate cross-sections of food packaging materials, for example to highlight the different layers in multilayer packaging systems (Woodward et al., 2004).

\subsection{Nanomechanical characterization of food packaging surfaces}

Several AFM-based techniques have been developed for the mechanical mapping of surfaces at the nanoscale, either quasi-static or dynamic (Passeri, Rossi, Tamburri, \& Terranova, 2013). Among the latter, AFM-based nanoindentation has been extensively used to probe the mechanical properties of soft material surfaces (Clifford \& Seah, 2005) and to study, for instance, the interaction forces between pharmaceutical excipient particles (Sindel \& Zimmermann, 2001), to

map mechanical properties of surfaces at the nanometer scale, e.g., via the so-called AFM force-volume mode (Krämer, Griepentrog, Bonaccurso, \& Cappella, 2014), as well as to detect subsurface features via stiffness tomography (Roduit et al., 2009). Dynamic methods for nanomechanical imaging include acoustic (Passeri, Bettucci, \& Rossi, 2010), ultrasonic (Kolosov et al., 1998), multifrequency and related methods (Cantrell, Cantrell, \& Lillehei, 2007; Cuberes, Alexander, Briggs, \& Kolosov, 2000; Garcia \& Herruzo, 2012; Garcia \& Proksch, 2013), Harmoni $X^{\oplus}$ mode (Sahin, Magonov, Su, Quate, \& Solgaard, 2007; Sikora \& Bednarz, 2012; S.; Wang \& Zhao, 2012; Liparoti, Sorrentino, Speranza, \& Titomanlio, 2017), NanoSwing mode (Sikora, Woszczyna, Friedemann, Ahlers, \& Kalbac, 2012; Sikora \& Bednarz, 2011). These methods are potentially extremely effective in terms of spatial resolution, range of measurable elastic modulus values, possibility of characterizing both elastic and viscoelastic properties (Killgore et al., 2011b), as well as capability of to detect subsurface features (Cantrell et al., 2007; Killgore, Kelly, Stafford, Fasolka, \& Hurley, 2011a; Parlak \& Degertekin, 2008; Reggente et al., 2017; Shekhawat \& Dravid, 2005). Overall, these methods have been successfully used in a broad range of materials, for example from hard minerals and coatings to soft polymers and biological samples, including food-related materials (Jones, 2016; Rossi et al., 2014).
Important properties of food packaging and food related materials are surface tension and wettability (Karbowiak, Debeaufort, \& Voilley, 2006). Dynamic AFM operating in amplitude modulation mode has been prosed as a method for nanoscale characterization of surface wettability (Amadei, Santos, Pehkonen, Verdaguer, \& Chiesa, 2013; Calò, Domingo, Santos, \& Verdaguer, 2015; Lai et al., 2014) and, thus, this method could be usefully employed to characterize activated food packaging materials.

PeakForce Tapping ${ }^{\circ}$ is a recently developed AFM mode in which the cantilever oscillates, at relatively low frequency, periodically tapping the sample surface. Instead of detecting the oscillation amplitude and maintaining it constant using the feedback loop as in standard tapping mode, the tip-sample interaction force is measured by the deflection of the cantilever and maintained constant during scanning through the feedback electronics. This technique enables the surface imaging with ultra-low tip-sample interaction forces (down to $10 \mathrm{pN}$ ) and the simultaneous acquisition of force curves with high speed and high lateral resolution. Based on this AFM mode, PeakForce Quantitative Nanomechanical Property Mapping (PeakForce QNM ${ }^{\circ}$ ) analyzes the acquired force curves to extract and map the quantitative local value of indentation modulus, deformation, tip-sample adhesion, and energy dissipation (Sweers, van der Werf, Bennink, \& Subramaniam, 2011). Modulus map obtained by $\mathrm{QNM}^{\circledR}$ were used to study starch/poly(vinyl alcohol) (S/PVA) cross-linked films reinforced with cellulose nanofibers (CNs), allowing the detection of CNs and of nanoscale amorphous structures in nanocomposites as prepared and after exposure to humid atmosphere (Panaitescu, Frone, Ghiurea, \& Chiulan, 2015). QNM ${ }^{\circledR}$ was also used to study the effect of CNs on poly(lactic acid) (PLA) matrix, also revealing the transition from the grained structure of amorphous PLA to a crystalline lamellar structure after annealing (Frone et al., 2016).

Another nanomechanical characterization technique which has been used in the analysis of food packaging materials is contact resonance AFM (CR-AFM). It is based on AFM contact mode and has been demonstrated to be suitable for quantitative nanomechanical characterization of elastic and viscoelastic materials in a broad range of elastic moduli, from stiff minerals to biological samples, both in air and in liquid. In CR-AFM, the tip is in contact with the sample surface with the cantilever-tip-sample system oscillating at ultrasonic frequency. The analysis of the resonance frequencies of the system allow one to evaluate the indentation modulus of an elastic sample (Passeri et al., 2007), while the simultaneous acquisition of the resonance frequencies and the corresponding quality factors enable the evaluation of the complex elastic modulus, i.e., storage and loss moduli and the loss tangent, of viscoelastic materials (Yuya, Hurley, \& Turner, 2011). CR-AFM was used to study the effect of reinforcement of starch-gelatin polymers through recycled cellulose at nanoscale level, evaluating the elastic modulus of the reinforced material and studying the homogeneity of the distribution of the cellulose into the polymer matrix (RodríguezCastellanos, Flores-Ruiz, Martínez-Bustos, Chiñas-Castillo, \& EspinozaBeltrán, 2015).

Multi-frequency AFM refers to a family of techniques in which the cantilever is excited with (at least) two signals at two different frequencies which are combined as a result of the nonlinear tip-sample interaction. Different techniques have been developed selecting different sets of frequencies, e.g., the first two modes (Garcia \& Herruzo, 2012) of the cantilever or two frequencies the difference of which matches one mode of the cantilever (Shekhawat \& Dravid, 2005), scan modes, feedback signals, and signals monitored and analyzed to evaluate the nanomechanical properties of the sample (Cantrell \& Cantrell, 2012). Limiting the discussion to food packaging materials, these methods have been used to study viscoelastic properties of polystyrene/ poly(caprolactone) blends, which are materials of interest in food packaging technology (Haviland et al., 2016; Jones, 2016).

As a final remark, although AFM-based techniques have been only marginally used to characterize food packaging materials, they are 
promising tools not only to quantitatively assess the mechanical properties of the materials (e.g. after surface treatments or reinforcement with nanofillers), but also to verify the uniformity of dispersion of nanomaterials in matrices by detecting surfacing or buried nanomaterials on the basis of their mechanical contrast with the surrounding matrix. For instance, force modulation microscopy (FMM) (Maivald et al., 1991) has been used to study dispersions of carbon nanotubes in polyol matrices (Wozniak et al., 2008). CR-AFM has been used to detect silica nanoparticles buried down to $165 \mathrm{~nm}$ under the surface of polystyrene films (Killgore, Kelly, et al., 2011), while FMM, heterodyne force microscopy (HFM), CR-AFM, and second harmonic ultrasonic AFM have been demonstrated to enable the detection of Au nanoparticles buried down to $1 \mu \mathrm{m}$ under the surface in polymeric matrices (Kimura, Kobayashi, Matsushige, \& Yamada, 2013). HarmoniX ${ }^{\oplus}$ mode was used to visualize diamond nanoparticles in polyaniline (PANI) micro- and nano-fibers (Passeri, Tamburri, Terranova, \& Rossi, 2015). Finally, ultrasound holography has been successfully used to detect different nanomaterials (e.g., silica- or carbon-based) into polymeric or biological matrices (Tetard, Passian, Lynch, et al., 2008; Tetard, Passian, Venmar, et al., 2008; Tetard, Passian, Farahi, \& Thundat, 2010; Soliman, Ding, \& Tetard, 2017).

\subsection{Raman spectroscopy and AFM on food packaging materials}

Vibrational spectroscopies, including Fourier transform infrared (FTIR) and Raman spectroscopy, are powerful tools to detect and identify chemical structure and molecular species of a material. In particular, in Raman spectroscopy the photons from a laser source are absorbed by a molecular system characterized by a set of vibrational energy states (Das \& Agrawal, 2011). If the system is in the fundamental state, the absorption of a photon leads to the transition to a virtual state and in the subsequent relaxation to a permitted vibrational state. If the system relaxes to the initial state the emitted photon has the same energy of the incident one (Rayleigh scattering), while if the final state is not the initial one the energy of the emitted photon is different, either lower or higher (Raman scattering). If the initial state is the fundamental one and the final state is the first excited vibrational energy level the scattered photon has lower energy (Stokes shift). If the initial state is the first vibrational state and the system relaxes to the fundamental state, the scattered photon has higher energy (anti-Stokes shift). A Raman spectrum thus characterized by a set of peaks, corresponding to the Raman shift values, which are related to the specific chemical bonds of the investigated material. When coupled with a scanning microscopy system, the intensity of Raman peaks can be mapped on the sample surface thus leading to the mapping of the chemical properties of the sample. Taking advance of the enhancement factor of the electric field in presence of metal nanostructured surfaces or nanoparticles due to localized surface plasmon resonance (LSPR), surface enhanced Raman spectroscopy (SERS) has been developed (Stiles, Dieringer, Shah, \& Van Duyne, 2008) which enables Raman spectroscopy to be performed with higher sensitivity on smaller amounts of sample. Among other applications, SERS has been demonstrated a powerful technique for the chemical analysis of food (Craig, Franca, \& Irudayaraj, 2013; Radu et al., 2016; Zheng \& He, 2014). The combination of SERS and AFM enabled the development of a new technique called tip-enhanced Raman spectroscopy (TERS), in which the LSPR induced field enhancement effect results from the use of a conductive AFM tip (Verma, 2017). Thus, the enhancement of the Raman signal does not depend on the conductance and the nanostructure of the sample surface, but is produced by the tip which scans the surface. Therefore, simultaneously to AFM topographical reconstruction, a local Raman spectrum can be acquired at each point of the scanned area. In addition, the intensity of the Raman signal corresponding to a specific chemical bond can be mapped on the sample surface. TERS has been used for different applications: in biology and organic chemistry to study proteins, viruses, DNA, porphyrins, and self-assembled monolayers, in materials science and nanotechnology to study carbon nanomaterials, in particular carbon nanotubes and graphene (DeckertGaudig, Taguchi, Kawata, \& Deckert, 2017), to investigate solid-liquid and electrochemical interfaces (Wang et al., 2017), as well as in semiconductor technology and electronic devices for nanoscale strain analysis (Lucia et al., 2017; Tarun, Hayazawa, \& Kawata, 2009).

To the best of our knowledge, despite its potential TERS has never used on food packaging materials. Conversely, among the different fields of applications, Raman spectroscopy and mapping have been used in food packaging to analyze the diffusivity of additives, their concentration profile and mass transport properties in food contact materials (Martinez-Lopez, Chalier, Guillard, Gontard, \& Peyron, 2014; Mauricio-Iglesias, Guillard, Gontard, \& Peyron, 2009), to map the distribution of nanofillers in matrices for food packaging materials, e.g., surface-modified montmorillonite (MMT) in cellulose foam (Ahmadzadeh et al., 2015), to elucidate the mode of action of antimicrobial food packaging material activated with benzyl isothiocyanate against Escherichia coli (Clemente, Aznar, Salafranca, \& Nerín, 2017). These applications of Raman spectroscopy suggest that TERS possess a high, yet unexplored, potential for the characterization of food packaging materials.

\subsection{Bacterial adhesion on food packaging surfaces probed with AFM}

Among other purposes, activation of surfaces for food packaging applications aims at developing antibacterial food contact materials (Rossi et al., 2017), for instance designing and realizing nanostructured surfaces (Hasan \& Chatterjee, 2015). Microbial colonization is a complex mechanism which involves the initial adhesion of a microorganism on a surface and the subsequent proliferation, with possible formation of biofilm. Bacterial adhesion is the result of both nonspecific physicochemical forces and specific interaction forces due to cellular structures like appendages. Several methods, including AFM, for quantitative evaluation of microbial colonization and biofilm formation have been developed (Dorobantu, Goss, \& Burrell, 2012; Pantanella, Valenti, Natalizi, Passeri, \& Berlutti, 2013). In particular, AFM can be used to quantitatively determine the adhesion forces between a single microbial cell and a surface as well as between two cells (Dufrêne, 2015). As AFM enables one to perform force spectroscopy, i.e., to directly measure the interaction force between the tip and a surface through the acquisition of cantilever deflection versus tip-sample distance curves, it has been used for about three decades to study material mechanical properties and tip-sample adhesion (Weisenhorn, Hansma, Albrecht, \& Quate, 1989). Adhesive forces can be nonspecific and due for example to adhesion between the materials of the tip and the surface or to capillary forces if the experiment is performed in air, or specific, if the cantilever is properly chemically functionalized. The latter is, for instance, the case the so-called chemical force microscopy (Noy, Vezenov, \& Lieber, 1997), which enables one to perform molecular recognition and mapping on a surface (Kienberger, Ebner, Gruber, \& Hinterdorfer, 2006). Moreover, the tip (or a tipless cantilever) can be functionalized by attaching a single cell or several cells to the probe (Angeloni et al., 2016). This can be obtained in different ways, by picking up a microbial cell through a cantilever chemically modified to increase the cell-cantilever adhesion (Bowen, Lovitt, \& Wright, 2001; Liu, Pinzón-Arango, Gallardo-Moreno, \& Camesano, 2010; Zeng, Müller, \& Meyer, 2014), by using colloidal probes, i.e., microspheres colonized by microbial cells and attached to the cantilever (Lau, Dutcher, Beveridge, \& Lam, 2009), as well as by physical entrapment using the recently developed FluidFM technique (Meister et al., 2009; Potthoff, Ossola, Zambelli, \& Vorholt, 2015). This cell probe can be used to perform force spectroscopy on a surface in order to study the adhesion mechanisms between the cell itself and the surface. Cell probe technique has been used to study the adhesion between different cells and surfaces, e.g.: Saccharomyces cerevisiae on freshly cleaved mica (Bowen, Hilal, Lovitt, \& Wright, 1998); Saccharomyces cerevisiae on mica, mica with hydrophobic coating, and 
protein-coated mica (Bowen et al., 2001); Staphylococcus xylosus, Staphylococcus epidermidis, Pseudomonas fluorescens, and Escherichia coli on fresh glass, hydrophilic glass, and mica (Zeng et al., 2014); Saccharomyces cerevisiae, Bacillus subtilis, and Escherichia coli on quartz (Kang \& Elimelech, 2009). Also, it has been used to study adhesion between Escherichia coli and human uroepithelial cells in presence of cranberry juice which is empirically considered to possess antibacterial benefic effects to the urinary tract (Liu et al., 2010).

To the best of our knowledge, nevertheless, cell probe methods have never been used to study microbial adhesion on food packaging materials. This filed of investigation, yet unexplored, represents nonetheless an extremely promising application of AFM methods to the nanoscale analysis of antimicrobial food packaging materials.

\section{Conclusions}

Active food packaging is a field of growing interest for researchers and enterprises whereas the main objectives are shelf life extension and food safety improvement. Activation process of plastic materials with antimicrobials or other activating ingredients could be monitored to find best process condition, combination of ingredient and material, way to be used in a food packaging design. Among the monitoring tools, AFM is finding ever-growing application, alone or more frequently in combination with other monitoring analysis like the SEM. However, in our opinion AFM is an irreplaceable analysis tool to reveal the topographical modification of plastic materials following the activation process. Moreover, new and advanced AFM techniques are developing to characterize structure and functionalities of plastic materials used for different purposes such as food packaging.

\section{Acknowledgements}

This research did not receive any specific grant from funding agencies in the public, commercial, or not-for-profit sectors.

\section{References}

Ahmadzadeh, S., Nasirpour, A., Keramat, J., Hamdami, N., Behzad, T., \& Desobry, S. (2015). Nanoporous cellulose nanocomposite foams as high insulated food packaging materials. Colloids and Surfaces A, 468, 201-210.

Amadei, C. A., Santos, S., Pehkonen, S. O., Verdaguer, A., \& Chiesa, M. (2013). Minimal invasiveness and spectroscopy-like footprints for the characterization of heterogeneous nanoscale wetting in ambient conditions. Journal of Physical Chemistry C, 117(40), 20819-20825.

Angeloni, L., Passeri, D., Reggente, M., Pantanella, F., Mantovani, D. \& Rossi, M. (2016). Microbial cells force spectroscopy by atomic force microscopy: A review. Nanoscience and Nanometrology, 2, 30-40.

Atarés, L., \& Chiralt, A. (2016). Essential oils as additives in biodegradable films and coatings for active food packaging. Trends in Food Science \& Technology, 48, 51-62.

Bar, G., Brandsch, R., \& Whangbo, M. H. (1998). Effect of viscoelastic properties of polymers on the phase shift in tapping mode atomic force microscopy. Langmuir, 14, 7343-7347.

Barish, J. A., \& Goddard, J. M. (2011). Topographical and chemical characterization of polymer surfaces modified by physical and chemical processes. Journal of Applied Polymer Science, 120, 2863-2871.

Bastarrachea, L. J., Wong, D. E., Roman, M. J., Lin, Z., \& Goddard, J. M. (2015). Active packaging coatings. Coatings, 5, 771-791.

Basu, A., Kundu, S., Sana, S., Halder, A., Abdullah, M. F., Datta, S., et al. (2017). Edible nano-bio-composite film cargo device for food packaging applications. Food Packaging and Shelf Life, 11, 98-105.

Bowen, W. R., Hilal, N., Lovitt, R. W., \& Wright, C. J. (1998). Direct measurement of the force of adhesion of a single biological cell using an atomic force microscope. Colloids and Surfaces A, 136, 231-234.

Bowen, W. R., Lovitt, R. W., \& Wright, C. J. (2001). Atomic force microscopy study of the adhesion of Saccharomyces cerevisiae. Journal of Colloid and Interface Science, 237, 54-61.

Brody, A. L., Bugusu, B., Han, J. H., Sand, C. K., \& McHugh, T. H. (2008). Innovative food packaging solutions. Journal of Food Science, 73, R107-R116.

Calò, A., Domingo, N., Santos, S., \& Verdaguer, A. (2015). Revealing water films structure from force reconstruction in dynamic AFM. Journal of Physical Chemistry C, 119(15), 8258-8265.

Cantrell, J. H., \& Cantrell, S. A. (2012). Cantilever dynamics: Theoretical modeling. In F. Marinello, D. Passeri, \& E. Savio (Eds.). Acoustic scanning probe microscopy (pp. 47100). Springer Berlin Heidelberg.
Cantrell, S. A., Cantrell, J. H., \& Lillehei, P. T. (2007). Nanoscale subsurface imaging via resonant difference-frequency atomic force ultrasonic microscopy. Journal of Applied Physics, 101, 114324.

Capitani, M. I., Matus-Basto, A., Ruiz-Ruiz, J. C., Santiago-García, J. L., Betancur-Ancona, D. A., Nolasco, S. M., et al. (2016). Characterization of biodegradable films based on Salvia hispanica L. protein and mucilage. Food and Bioprocess Technology, 9, 1276-1286.

Chaichi, M., Hashemi, M., Badii, F., \& Mohammadi, A. (2017). Preparation and characterization of a novel bionanocomposite ediblefilm based on pectin and crystalline nanocellulose. Carbohydrate Polymers, 157, 167-175.

Cichello, S. A. (2015). Oxygen absorbers in food preservation: A review. Journal of Food Science \& Technology, 52, 1889-1895.

Clemente, I., Aznar, M., Salafranca, J., \& Nerín, C. (2017). Raman spectroscopy, electronic microscopy and SPME-GC-MS to elucidate the mode of action of a new antimicrobial food packaging material. Analytical and Bioanalytical Chemistry, 409, 1037-1048.

Clifford, C. A., \& Seah, M. P. (2005). Quantification issues in the identification of nanoscale regions of homopolymers using modulus measurement via AFM nanoindentation. Applied Surface Science, 252, 1915-1933.

Corradini, C., Alfieri, I., Cavazza, A., Lantano, C., Lorenzi, A., Zucchetto, N., et al. (2013) Antimicrobial films containing lysozyme for active packaging obtained by sol-gel technique. Journal of Food Engineering, 119, 580-587.

Craig, A. P., Franca, A. S., \& Irudayaraj, J. (2013). Surface-enhanced Raman spectroscopy applied to food safety. Annual Review of Food Science and Technology, 4, 369-380.

Cuberes, M. T., Alexander, H. E., Briggs, G. A. D., \& Kolosov, O. V. (2000). Heterodyne force microscopy of PMMA/rubber nanocomposites: Nanomapping of viscoelastic response at ultrasonic frequencies. Journal of Physics D: Applied Physics, 33, 2347-2355.

Damaj, Z., Joly, C., \& Guillon, E. (2015). Toward new polymeric oxygen scavenging systems: formation of poly(vinyl alcohol) oxygen scavenger film. Packaging Technology and Science, 28, 293-302.

Das, R. S., \& Agrawal, Y. K. (2011). Raman spectroscopy: Recent advancements, techniques and applications. Vibrational Spectroscopy, 57, 163-176.

Davoodi, M., Kavoosi, G., \& Shakeri, R. (2017). Preparation and characterization of potato starch-thymol dispersion and film as potential antioxidant and antibacterial materials. International Journal of Biological Macromolecules, 104, 173-179.

Deckert-Gaudig, T., Taguchi, A., Kawata, S., \& Deckert, V. (2017). Tip-enhanced Raman spectroscopy - from early developments to recent advances. Chemical Society Reviews, 46, 4077-4110.

Dehnavi, A. S., Aroujalian, A., Raisi, A., \& Fazel, S. (2013). Preparation and characterization of polyethylene/silver nanocomposite films with antibacterial activity. Journal of Applied Polymer Science, 127/2, 1180-1190.

Denis-Rohr, A., Bastarrachea, L. J., \& Goddard, J. M. (2015). Antimicrobial efficacy of Nhalamine coatings prepared via dip and spray layer-by-layer deposition. Food and Bioproducts Processing, 96, 12-19.

Dobrucka, R., \& Cierpiszewski, R. (2014). Active and intelligent packaging food - research and development - a review. Polish Journal of Food and Nutrition Sciences, 64, $7-15$.

Dorobantu, L. S., Goss, G. G., \& Burrell, R. E. (2012). Atomic force microscopy: A nanoscopic view of microbial cell surfaces. Micron, 43, 1312-1322.

Dufrêne, Y. F. (2015). Sticky microbes: Forces in microbial cell adhesion. Trends in Microbiology, 23, 376-382.

Ercolini, D., Ferrocino, I., La Storia, A., Mauriello, G., Gigli, S., Masi, P., et al. (2010). Development of spoilage microbiota in beef stored in nisin activated packaging. Food Microbiology, 27, 137-143.

Ercolini, D., La Storia, A., Villani, F., \& Mauriello, G. (2006). Effect of a bacteriocin activated polythene film on Listeria monocytogenes as evaluated by viable staining and epifluorescence microscopy. Journal of Applied Microbiology, 100, 765-772.

Fang, Z., Zhao, Y., Warner, R. D., \& Johnson, S. K. (2017). Active and intelligent packaging in meat industry. Trends in Food Science \& Technology, 61, 60-71.

Ferrocino, I., La Storia, A., Torrieri, E., Spagna Musso, S., Mauriello, G., Villani, F., et al. (2013). Antimicrobial packaging to retard the growth of spoilage bacteria and to reduce the release of volatile metabolites in meat stored under vacuum at $1^{\circ} \mathrm{C}$. Journal of Food Protection, 76, 52-58.

Frone, A. N., Panaitescu, D. M., Chiulan, I., Nicolae, C. A., Vuluga, Z., Vitelaru, C., et al. (2016). The effect of cellulose nanofibers on the crystallinity and nanostructure of poly(lactic acid) composites. Journal of Materials Science, 51, 9771-9791.

Galdi, M. R., Nicolais, V., Di Maio, L., \& Incarnato, L. (2008). Production of active PET films: Evaluation of scavenging activity. Packaging Technology and Science, 21, $257-268$.

Garcia, R., \& Herruzo, E. T. (2012). The emergence of multifrequency force microscopy. Nature Nanotechnology, 7, 217-226.

García, R., \& Pérez, R. (2002). Dynamic atomic force microscopy methods. Surface Science Reports, 47, 197-301.

Garcia, R., \& Proksch, R. (2013). Nanomechanical mapping of soft matter by bimodal force microscopy. European Polymer Journal, 49, 1897-1906.

Ghasemlou, M., Aliheidari, N., Fahmi, R., Shojaee-Aliabadi, S., Keshavarz, B., Cran, M. J., et al. (2013). Physical, mechanical and barrier properties of corn starch films incorporated with plant essential oils. Carbohydrate Polymers, 98, 1117-1126.

Gouvea, D. M., Mendonça, R. C. S., Soto, M. L., \& Cruz, R. S. (2015). Acetate cellulose film with bacteriophages for potential antimicrobial use in food packaging. LebensmittelWissenschaft und -Technologie- Food Science and Technology, 63, 85-91.

Grigoriu, A. M., Luca, C., Horoba, E., \& Dunca, S. (2013). Antimicrobial polymer films functionalized with cyclodextrins. Revista de Chimie, 64, 606-611.

Guarda, A., Rubilar, J. F., Miltz, J., \& Galotto, M. J. (2011). The antimicrobial activity of microencapsulated thymol and carvacrol. International Journal of Food Microbiology, 
$146,144-150$.

Hasan, J., \& Chatterjee, K. (2015). Recent advances in engineering topography mediated antibacterial surfaces. Nanoscale, 7, 15568-15575.

Haviland, D. B., van Eysden, C. A., Forchheimer, D., Platz, D., Kassa, H. G., \& Leclere, P. (2016). Probing viscoelastic response of soft material surfaces at the nanoscale. Soft Matter, 12, 619-624.

Hosseini, S. F., Rezaei, M., Zandi, M., \& Farahmandghavi, F. (2016). Development of bioactive fish gelatin/chitosan nanoparticles composite films with antimicrobial properties. Food Chemistry, 194, 1266-1274.

Ingallina, C., Rinaldi, F., Bogni, A., Ponti, J., Passeri, D., Reggente, M., et al. (2016). Niosomal approach to brain delivery: Development, characterization and in vitro toxicological studies. International Journal of Pharmaceutics, 511, 969-982.

Jamshidian, M., Tehrany, E. A., Cleymand, F., Lecontec, S., Falher, T., \& Desobry, S. (2012a). Effects of synthetic phenolic antioxidants on physical, structural, mechanical and barrier properties of poly lactic acid film. Carbohydrate Polymers, 87, 1763-1773.

Jamshidian, M., Tehrany, E. A., Imran, M., Akhtar, M. J., Cleymand, F., \& Desobry, S. (2012b). Structural, mechanical and barrier properties of active PLA-antioxidant films. Journal of Food Engineering, 110, 380-389.

Javidi, Z., Hosseini, S. F., \& Rezaei, M. (2016). Development of flexible bactericidal films based on poly(lactic acid) and essential oil and its effectiveness to reduce microbial growth of refrigerated rainbow trout. Lebensmittel-Wissenschaft und-Technologie- Food Science and Technology, 72, 251-260.

Johansson, K., Kotkamo, S., Rotabakk, B. T., Johansson, C., Kuusipalo, J., Jonsson, L. J., et al. (2014). Extruded polymer films for optimal enzyme-catalyzed oxygen scavenging. Chemical Engineering Science, 108, 1-8.

Jones, O. G. (2016). Developments in dynamic atomic force microscopy techniques to characterize viscoelastic behaviors of food materials at the nanometer-scale. Current Opinion in Food Science, 9, 77-83.

Kang, S., \& Elimelech, M. (2009). Bioinspired single bacterial cell force spectroscopy. Langmuir, 25, 9656-9659.

Karam, L., Jama, C., Dhulster, P., \& Chihib, N. E. (2013). Study of surface interactions between peptides, materials and bacteria for setting up antimicrobial surfaces and active food packaging. Journal of Materials and Environmental Science, 4, 798-821.

Karbowiak, T., Debeaufort, F., \& Voilley, A. (2006). Importance of surface tension characterization for food, pharmaceutical and packaging products: A review. Critical Reviews in Food Science and. Nutrition, 46(5), 391-407.

Khalaj, M. J., Ahmadi, H., Lesankhosh, R., \& Khalaj, G. (2016). Study of physical and mechanical properties of polypropylene nanocomposites for food packaging application: Nano-clay modified with iron nanoparticles. Trends in Food Science \& Technology, 51, 41-48.

Kienberger, F., Ebner, A., Gruber, H. J., \& Hinterdorfer, P. (2006). Molecular recognition imaging and force spectroscopy of single biomolecules. Accounts of Chemical Research, 39, 29-36.

Killgore, J. P., Kelly, J. Y., Stafford, C. M., Fasolka, M. J., \& Hurley, D. C. (2011a). Quantitative subsurface contact resonance force microscopy of model polymer nanocomposites. Nanotechnology, 22, 175706.

Killgore, J. P., Yablon, D. G., Tsou, A. H., Gannepalli, A., Yuya, P. A., Turner, J. A., et al. (2011b). Viscoelastic property mapping with contact resonance force microscopy. Langmuir, 27, 13983-13987.

Kimura, K., Kobayashi, K., Matsushige, K., \& Yamada, H. (2013). Imaging of Au nanoparticles deeply buried in polymer matrix by various atomic force microscopy techniques. Ultramicroscopy, 133(Supplement C), 41-49.

Kolosov, O. V., Castell, M. R., Marsh, C. D., Briggs, G. A. D., Kamins, T. I., \& Williams, R. S. (1998). Imaging the elastic nanostructure of $\mathrm{Ge}$ islands by ultrasonic force microscopy. Physical Review Letters, 81, 1046-1049.

Koontz, J. L., Marcy, J. E., O'Keefe, S. F., Duncan, S. E., Long, T. E., \& Moffitt, R. D. (2010). Polymer processing and characterization of LLDPE films laded with alphatocopherol, quercetin, and their cyclodextrin inclusion complexes. Journal of Applied Polymer Science, 117, 2299-2309.

Krämer, G., Griepentrog, M., Bonaccurso, E., \& Cappella, B. (2014). Study of morphology and mechanical properties of polystyrene-polybutadiene blends with nanometre resolution using AFM and force-distance curves. European Polymer Journal, 55(Supplement C), 123-134.

La Storia, A., Mauriello, G., Villani, F., \& Ercolini, D. (2013). Coating-activation and antimicrobial efficacy of different polyethylene films with a nisin-based solution. Food and Bioprocess Technology, 6, 2770-2779.

Lai, C.-Y., Tang, T.-C., Amadei, C. A., Marsden, A. J., Verdaguer, A., Wilson, N., et al. (2014). A nanoscopic approach to studying evolution in graphene wettability. Carbon, 80(Supplement C), 784-792.

Lau, P. C. Y., Dutcher, J. R., Beveridge, T. J., \& Lam, J. S. (2009). Absolute quantitation of bacterial biofilm adhesion and viscoelasticity by microbead force spectroscopy. Biophysical Journal, 96, 2935-2948.

Lei, J., Yang, L., Zhan, Y., Wang, Y., Ye, T., Li, Y., et al. (2014). Plasma treated polyethylene terephthalate/polypropylene films assembled with chitosan and various preservatives for antimicrobial food packaging. Colloids and Surfaces B: Biointerfaces, 114, 60-66.

Leonard, L., Beji, O., Arnould, C., Noirot, E., Bonnotte, A., Gharsallaoui, A., et al. (2015). Preservation of viability and anti-Listeria activity of lactic acid bacteria, Lactococcus lactis and Lactobacillus paracasei, entrapped in gelling matrices of alginate or alginate/ caseinate. Food Control, 47, 7-19.

Liparoti, S., Sorrentino, A., Speranza, V., \& Titomanlio, G. (2017). Multiscale mechanical characterization of iPP injection molded samples. European Polymer Journal, 90(Supplement C), 79-91.

Liu, Y., Pinzón-Arango, P. A., Gallardo-Moreno, A. M., \& Camesano, T. A. (2010). Direct adhesion force measurements between $E$. coli and human uroepithelial cells in cranberry juice cocktail. Molecular Nutrition \& Food Research, 54, 1744-1752.

Lucia, A., Cacioppo, O. A., Iulianella, E., Latessa, L., Moccia, G., Passeri, D., et al. (2017). Capability of tip-enhanced Raman spectroscopy about nanoscale analysis of strained silicon for semiconductor devices production. Applied Physics Letters, 110, 103-105.

Maiti, M., \& Bhowmick, A. K. (2006). New insights into rubber-clay nanocomposites by AFM imaging. Polymer, 47, 6156-6166.

Maivald, P., Butt, H. J., Gould, S. A., Prater, C. B., Drake, B., Gurley, J. A., et al. (1991). Using force modulation to image surface elasticities with the atomic force microscope. Nanotechnology, 2, 103-106.

Maresca, D., De Prisco, A., La Storia, A., Cirillo, T., Esposito, F., \& Mauriello, G. (2016). Microencapsulation of nisin in alginate beads by vibrating technology: Preliminary investigation. LWT - Food Science and Technology, 66, 436-443.

Marinello, F., Balcon, M., Schiavuta, P., Carmignato, S., \& Savio, E. (2011). Thermal drift study on different commercial scanning probe microscopes during the initial warming-up phase. Measurement Science and Technology, 22, 94016.

Marinello, F., Bariani, P., Carmignato, S., \& Savio, E. (2009). Geometrical modelling of scanning probe microscopes and characterization of errors. Measurement Science and Technology, 20/8, 84013.

Marinello, F., Schiavuta, P., Vezzù, S., Patelli, A., Carmignato, S., \& Savio, E. (2011). Atomic force acoustic microscopy for quantitative nanomechanical characterization. Wear, 271, 534-538.

Martinez-Lopez, B., Chalier, P., Guillard, V., Gontard, N., \& Peyron, S. (2014). Determination of mass transport properties in food/packaging systems by local measurement with Raman microspectroscopy. Journal of Applied Polymer Science, 131(21).

Mauricio-Iglesias, M., Guillard, V., Gontard, N., \& Peyron, S. (2009). Application of FTIR and Raman microspectroscopy to the study of food/packaging interactions. Food Additives \& Contaminants: Part A, 26, 1515-1523.

Mauriello, G. (2016). Control of microbial activity using antimicrobial packaging. In J. Barros-Velazquez (Ed.). Antimicrobial food packaging (pp. 141-150). Elsevier, Academic Press.

Mauriello, G., De Luca, E., La Storia, A., Villani, F., \& Ercolini, D. (2005). Antimicrobial activity of a nisin-activated plastic film for food packaging. Letters in Applied Microbiology, 41, 464-469.

Mauriello, G., Ercolini, D., La Storia, A., Casaburi, A., \& Villani, F. (2004). Development of polyethylene films for food packaging activated with an antlisterial bacteriocin from Lactobacillus curvatus 32Y. Journal of Applied Microbiology, 97, 314-322.

Mauriello, G., \& Villani, F. (2011). Bacteriocins in plastics. In J. Lagaron, M. J. Ocio, \& A. Lopez-Rubio (Eds.). Antimicrobial polymers (pp. 117-158). Wiley.

Meister, A., Gabi, M., Behr, P., Studer, P., Vörös, J., Niedermann, P., et al. (2009). FluidFM: Combining atomic force microscopy and nanofluidics in a universal liquid delivery system for single cell applications and beyond. Nano Letters, 9, 2501-2507.

Noy, A., Vezenov, D. V., \& Lieber, C. M. (1997). Chemical force microscopy. Annual Review of Materials Science, 27, 381-421.

Ortega-Toro, R., Jiménez, A., Talens, P., \& Chiralt, A. (2014). Effect of the incorporation of surfactants on the physical properties of corn starch films. Food Hydrocolloids, 38, 66-75.

Otoni, C. G., Espitia, P. J. P., Avena-Bustillos, R. J., \& McHugh, T. H. (2017). Trends in antimicrobial food packaging systems: Emitting sachets and absorbent pads. Food Research International, 83, 60-73.

Panaitescu, D. M., Frone, A. N., Ghiurea, M., \& Chiulan, I. (2015). Influence of storage conditions on starch/PVA films containing cellulose nanofibers. Industrial Crops and Products, 70, 170-177.

Pantanella, F., Valenti, P., Natalizi, T., Passeri, D., \& Berlutti, F. (2013). Analytical techniques to study microbial biofilm on abiotic surfaces: Pros and cons of the main techniques currently in use. Annali di Igiene, 25, 31-42.

Parlak, Z., \& Degertekin, F. L. (2008). Contact stiffness of finite size subsurface defects for atomic force microscopy: Three-dimensional finite element modeling and experimental verification. Journal of Applied Physics, 103, 114910.

Passarinho, A. T. P., Dias, N. F., Camilloto, G. P., Cruz, R. S., Otoni, C. G., Moraes, A. R. F., et al. (2014). Sliced bread preservation through oregano essential oil-containing sachet. Journal of Food Process Engineering, 37, 53-62.

Passeri, D., Bettucci, A., Germano, M., Rossi, M., Alippi, A., Fiori, A., et al. (2007). Local indentation modulus characterization via two contact resonance frequencies atomic force acoustic microscopy. Microelectronic Engineering, 84, 490-494.

Passeri, D., Bettucci, A., \& Rossi, M. (2010). Acoustic and atomic force microscopy for the mechanical characterization of thin films. Analytical and Bioanalytical Chemistry, 396, 2769-2783.

Passeri, D., Rossi, M., Tamburri, E., \& Terranova, M. L. (2013). Mechanical characterization of polymeric thin films by atomic force microscopy based techniques. Analytical and Bioanalytical Chemistry, 405, 1463-1478.

Passeri, D., Tamburri, E., Terranova, M. L., \& Rossi, M. (2015). Polyaniline-nanodiamond fibers resulting from the self-assembly of nano-fibrils: A nanomechanical study, Nanoscale, 7, 14358-14367.

Pereira de Abreu, D. A., Cruz, J. M., \& Losada, P. P. (2012). Active and intelligent packaging for the food industry. Food Reviews International, 28, 146-187.

Persico, P., Ambrogi, V., Carfagna, C., Cerruti, P., Ferrocino, I., \& Mauriello, G. (2009). Nanocomposite polymer films containing carvacrol for antimicrobial active packaging. Polymer Engineering \& Science, 49, 1447-1455.

Potthoff, E., Ossola, D., Zambelli, T., \& Vorholt, J. A. (2015). Bacterial adhesion force quantification by fluidic force microscopy. Nanoscale, 7, 4070-4079.

Radford, D., Guild, B., Strange, P., Ahmed, R., Lim, L. T., \& Balamurugan, S. (2017). Characterization of antimicrobial properties of Salmonella phage Felix O1 and Listeria phage A511 embedded in xanthan coatings on Poly(lactic acid) films. Food Mirobiology, 66, 117-128.

Radu, A. I., Kuellmer, M., Giese, B., Huebner, U., Weber, K., Cialla-May, D., et al. (2016). 
Surface-enhanced Raman spectroscopy (SERS) in food analytics: Detection of vitamins B2 and B12 in cereals. Talanta, 160, 289-297.

Raghavan, D., Gu, X., Nguyen, T., VanLandingham, M., \& Karim, A. (2000). Mapping polymer heterogeneity using atomic force microscopy phase imaging and nanoscale indentation. Macromolecules, 33, 2573-2583.

Reggente, M., Passeri, D., Angeloni, L., Scaramuzzo, F. A., Barteri, M., De Angelis, F., et al. (2017). Detection of stiff nanoparticles within cellular structures by contact resonance atomic force microscopy subsurface nanomechanical imaging. Nanoscale, 9, 5671-5676.

Rodríguez-Castellanos, W., Flores-Ruiz, F. J., Martínez-Bustos, F., Chiñas-Castillo, F., \& Espinoza-Beltrán, F. J. (2015). Nanomechanical properties and thermal stability of recycled cellulose reinforced starch-gelatin polymer composite. Journal of Applied Polymer Science, 132, 41787.

Roduit, C., Sekatski, S., Dietler, G., Catsicas, S., Lafont, F., \& Kasas, S. (2009). Stiffness tomography by atomic force microscopy. Biophysical Journal, 97, 674-677.

Rossi, M., Cubadda, F., Dini, L., Terranova, M. L., Aureli, F., Sorbo, A., et al. (2014). Scientific basis of nanotechnology, implications for the food sector and future trends. Trends in Food Science \& Technology, 40, 127-148.

Rossi, M., Passeri, D., Sinibaldi, A., Angjellari, M., Tamburri, E., Sorbo, A., et al. (2017). Nanotechnology for food packaging and food quality assessment. Advances in Food \& Nutrition Research, 82, 149-204.

Sadeghi, K., \& Shahedi, M. (2016). Physical, mechanical, and antimicrobial properties of ethylene vinyl alcohol copolymer/chitosan/nano-ZnO (ECNZn) nanocomposite films incorporating glycerol plasticizer. Food Measure, 10, 137-147.

Sadeghnejad, A., Aroujalian, A., Raisi, A., \& Fazel, S. (2014). Antibacterial nano silver coating on the surface of polyethylene films using corona discharge. Surface and Coatings Technology, 245, 1-8.

Sahin, O., Magonov, S., Su, C., Quate, C. F., \& Solgaard, O. (2007). An atomic force microscope tip designed to measure time-varying nanomechanical forces. Nature Nanotechnology, 2, 507-514.

Saini, S., Falco, C. Y., Belgacem, M. N., \& Bras, J. (2016). Surface cationized cellulose nanofibrils for the production of contactactive antimicrobial surfaces. Carbohydrate Polymers, 135, 239-247.

Salarbashi, D., Mortazavi, S. A., Noghabi, M. S., Bazzaz, B. S. F., Sedaghat, N., Ramezani, M., et al. (2016). Development of new active packaging film made from a soluble soybean polysaccharide incorporating $\mathrm{ZnO}$ nanoparticles. Carbohydrate Polymers, $140,220-227$.

Salarbashi, D., Tajik, S., Ghasemlou, M., Shojaee-Aliabadi, S., Noghabi, M. S., \& Khaksar, R. (2013). Characterization of soluble soybean polysaccharide film incorporated essential oil intended for food packaging. Carbohydrate Polymers, 98, 1127-1136.

Scarfato, P., Avallone, E., Galdi, M. R., Di Maio, L., \& Incarnato, L. (2017). Preparation, characterization, and oxygen scavenging capacity of biodegradable alpha-tocopherol/PLA microparticles for active food packaging applications. Polymer Composites, 38, 981-986.

Shekhawat, G. S., \& Dravid, V. P. (2005). Nanoscale imaging of buried structures via scanning near-field ultrasound holography. Science, 310, 89-92.

Shojaee-Aliabadi, S., Hosseini, H., Mohammadifar, M. A., Mohammadi, A., Ghasemlou, M., Ojagh, S. M., et al (2013). Characterization of antioxidant-antimicrobial k-carrageenan films containing Satureja hortensis essential oil. International Journal of Biological Macromolecules, 52, 116-124.

Sikora, A., \& Bednarz, Ł. (2012). Mapping of the surface's mechanical properties through analysis of torsional cantilever bending in dynamic force microscopy. In F. Marinello, D. Passeri, \& E. Savio (Eds.). Acoustic scanning probe microscopy (pp. 325-3500). Springer Berlin Heidelberg.

Sikora, A., \& Bednarz, E. (2011). Mapping of mechanical properties of the surface by utilization of torsional oscillation of the cantilever in atomic force microscopy Central Europe Journal of Physics, 9(2), 372-379.

Sikora, A., Woszczyna, M., Friedemann, M., Ahlers, F. J., \& Kalbac, M. (2012). AFM diagnostics of graphene-based quantum Hall devices. Micron, 43(2), 479-486.

Sindel, U., \& Zimmermann, I. (2001). Measurement of interaction forces between individual powder particles using an atomic force microscope. Powder Technology, 117(3), 247-254.

Soliman, M., Ding, Y., \& Tetard, L. (2017). Nanoscale subsurface imaging. Journal of Physics: Condensed Matter, 29(17), 173001.

Stiles, P. L., Dieringer, J. A., Shah, N. C., \& Van Duyne, R. P. (2008). Surface-enhanced Raman spectroscopy. Annual Review of Analytical Chemistry, 1, 601-626.

Stoleru, E., Dumitriu, R. P., Munteanu, B. S., Zaharescu, T., Tanase, E. E., Mitelut, A., et al. (2016). Novel procedure to enhance PLA surface properties by chitosan irreversible immobilization. Applied Surface Science, 367, 407-417.
Sung, S.-Y., Sin, L. T., Tee, T.-T., Bee, S.-T., \& Rahmat, A. R. (2014). Effects of Allium sativum essence oil as antimicrobial agent for food packaging plastic film. Innovative Food Science \& Emerging Technologies, 26, 406-414.

Sweers, K., van der Werf, K., Bennink, M., \& Subramaniam, V. (2011). Nanomechanical properties of $\alpha$-synuclein amyloid fibrils: A comparative study by nanoindentation, harmonic force microscopy, and peakforce QNM. Nanoscale Research Letters, 6, 270.

Tarun, A., Hayazawa, N., \& Kawata, S. (2009). Tip-enhanced Raman spectroscopy for nanoscale strain characterization. Analytical and Bioanalytical Chemistry, 394, 1775-1785.

Tetard, L., Passian, A., Farahi, R. H., \& Thundat, T. (2010). Atomic force microscopy of silica nanoparticles and carbon nanohorns in macrophages and red blood cells. Ultramicroscopy, 110(6), 586591.

Tetard, L., Passian, A., Lynch, R. M., Voy, B. H., Shekhawat, G., Dravid, V., et al. (2008) Elastic phase response of silica nanoparticles buried in soft matter. Applied Physics Letters, 93, 133113.

Tetard, L., Passian, A., Venmar, K. T., Lynch, R. M., Voy, B. H., Shekhawat, G., et al. (2008). Imaging nanoparticles in cells by nanomechanical holography. Nature Nanotechnology, 3, 501-505.

The Commission of the European Communities. (2004). Regulation (EC) No. 1935/2004 of the European Parliament and of the Council of 27 October 2004 on materials and articles intended to come into contact with food and repealing Directives 80/590/ EEC and 89/109/EEC. Official Journal of the European Union, 2004 L338/4.

Theapsak, S., Watthanaphanit, A., \& Rujiravanit, R. (2012). Preparation of chitosancoated polyethylene packaging films by DBD plasma treatment. Applied Materials \& Interfaces, 4, 2474-2482.

Tornuk, F., Hancer, M., Sagdic, O., \& Yetim, H. (2015). LLDPE based food packaging incorporated with nanoclays grafted with bioactive compounds to extend shelf life of some meat products. LWT - Food Science and Technology, 64, 540-546.

Valdés, A., Ramos, M., Beltrán, A., Jimémez, A., \& Garrigós, M. C. (2017). State of the art of antimicrobial edible coatings for food packaging applications. Coatings, 7, 56.

Verma, P. (2017). Tip-enhanced Raman spectroscopy: Technique and recent advances. Chemical Reviews, 117, 6447-6466.

Wang, X., Huang, S.-C., Huang, T.-X., Su, H.-S., Zhong, J.-H., Zeng, Z.-C., et al. (2017). Tip-enhanced Raman spectroscopy for surfaces and interfaces. Chemical Society Reviews, 46, 4020-4041.

Wang, S., \& Zhao, G. (2012). Quantitative characterization of the electrospun gelatinchitosan nanofibers by coupling scanning electron microscopy and atomic force microscopy. Materials Letters, 79(Supplement C), 14-17.

Weisenhorn, A. L., Hansma, P. K., Albrecht, T. R., \& Quate, C. F. (1989). Forces in atomic force microscopy in air and water. Applied Physics Letters, 54, 2651-2653.

Wong, D. E., Andler, S. M., Lincoln, C., Goddard, J. M., \& Talbert, J. N. (2017). Oxygen scavenging polymer coating prepared by hydrophobic modification of glucose oxidase. Journal of Coatings Technology and Research, 14, 489-495.

Woodward, I., Ebbens, S., Zhang, J., Luk, S., Patel, N., \& Roberts, C. J. (2004). A combined imaging, microthermal and spectroscopic study of a multilayer packaging system. Packaging Technology and Science, 17, 129-138.

Wozniak, M. J., Ryszkowska, J., Szymborski, T., Chen, G., Tateishi, T., \& Kurzydłowski, K. $\mathrm{J}$. (2008). Application of phase imaging and force modulation mode for description of dispersion of carbon nanotubes in polyol matrix. Materials Science-Poland, 26(1), 103-106.

Wu, C., Tian, J., Li, S., Wu, T., Hu, Y., Chen, S., et al. (2016). Structural properties of films and rheology of film-forming solutions of chitosan gallate for food packaging. Carbohydrate Polymers, 146, 10-19.

Wu, T., Wu, C., Fu, S., Wang, L., Yuan, C., Chen, S., et al. (2017). Integration of lysozyme into chitosan nanoparticles for improving antibacterial activity. Carbohydrate Polymers, 155, 192-200.

Xing, Y., Xu, Q., Yang, S. X., Chen, C., Tang, Y., Sun, S., et al. (2016). Preservation mechanism of chitosan-based coating with cinnamon oil for fruits storage based on sensor data. Sensors, 16, 1111.

Yin, M., Chen, X., Li, R., Huang, D., Fan, X., Ren, X., et al. (2016). Preparation and characterization of antimicrobial PVA hybrid films with N-halamine modified chitosan nanospheres. Journal of Applied Polymer Science, 133, 44204.

Yuya, P. A., Hurley, D. C., \& Turner, J. A. (2011). Relationship between Q-factor and sample damping for contact resonance atomic force microscope measurement of viscoelastic properties. Journal of Applied Physics, 109, 11.

Zeng, G., Müller, T., \& Meyer, R. L. (2014). Single-cell force spectroscopy of bacteria enabled by naturally derived proteins. Langmuir, 30, 4019-4025.

Zheng, J., \& He, L. (2014). Surface-enhanced Raman spectroscopy for the chemical analysis of food. Comprehensive Reviews in Food Science and Food Safety, 13, 317-328. 